09,08

\title{
Фотолюминесценция диоксида циркония, допированного иттербием
}

\author{
(C) С.Н. Шкерин ${ }^{1}$, Е.С. Ульянова ${ }^{2}$, Э.Г. Вовкотруб ${ }^{1}$ \\ ${ }^{1}$ Институт высокотемпературной электрохимии УрО РАН, \\ Екатеринбург, Россия \\ ${ }^{2}$ Институт химии твердого тела УрО РАН, \\ Екатеринбург, Россия \\ E-mail: shkerin@mail.ru
}

Поступила в Редакцию 6 декабря 2021 г.

В окончательной редакции 6 декабря 2021 r.

Принята к публикации 15 декабря 2021 г.

Для образцов диоксида циркония, допированных 10, 20 и 25\% оксида иттербия, изучены спектры комбинационного рассеяния света. Работа посвящена области больших волновых чисел. Использованы источники с длиной волны 785 и $532 \mathrm{~nm}$. Показано не только наличие полос, обусловленных фотолюминесценцией катионов иттербия, но и наличие стоксовских рефлексов, идентифицированных в спектрах при использовании разных источников света.

Ключевые слова: $\mathrm{Zr}(\mathrm{Yb}) \mathrm{O}_{2}$, комбинационное (рамановское) рассеяние света, люминесценция, ассоциация дефектов.

DOI: 10.21883/FTT.2022.04.52187.252

\section{1. Введение}

Допированный диоксид циркония находит широкое применение как твердый кислородпроводящий электролит в высокотемпературных электрохимических устройствах [1-10]. Для прогнозирования свойств данных электролитов важно понимать их дефектную структуру и, особенно, взаимодействие точечных дефектов между собой. Такое взаимодействие создает особенности поведения приповерхностного слоя материалов [11-13], границ зерен $[14,15]$, проводимости [16-18], включая ее стабильность во времени [19-21], аномалии теплопроводности при низких температурах [22,23]. Методов исследования ближнего порядка не так много. Среди них наиболее доступны методы колебательной спектроскопии. Однако спектры комбинационного (рамановского) рассеяния света, которые для материалов с ГЦК-структурой типа флюорита обычно дают одну полосу с $T_{2 g}$ симметрией [24], в случае материалов на основе диоксида циркония показывают существенно более сложную картину. Пример таких сложных спектров, полученных для монокристаллических образцов, представлен в [25]. Анализ механизмов рассеяния света [26] показывает, что отделить стоксовские полосы от других эффектов можно при использовании монохроматических источников с разной длиной волны, ибо только линейные стоксовские эффекты не зависят от длины волны накладываемого возмущения. В работе [27] это продемонстрировано с применением четырех разных лазеров для анализа диоксида церия и ряда оксидов редкоземельных металлов. В первой части настоящей работы два разных монохроматичных источника света с длинами волн
532 и $785 \mathrm{~nm}$ использованы для выделения стоксовских рефлексов, что позволило изучить ближней порядок материалов на основе диоксида циркония с применением анализа достоверно стоксовских рефлексов [28].

Использование катионов с $f$-электронами (редкоземельные металлы, РЗМ) в качестве допанта открывает новые возможности. Переходы между $f$-уровнями локализованных РЗМ-металлов хорошо изучены. Внесение таких катионов в среду приводит к расщеплению энергетических уровней под действием поля, окружающего катион. В том числе в это расщепление вносит вклад и координационное окружение анионами, что, в принципе, позволяет определять координационное число катиона. Однако эти эффекты слабы и требуют продуманного выбора РЗМ-катиона. Катион иттербия выгодно отличается наличием малого количества активных линий [29], что повышает шумозащищённость таких экспериментов. Именно для катиона иттербия, правда, во фторидной матрице флюорита $\mathrm{CaF}_{2}$, уже рассмотрено влияние симметрии окружения на расщепление полосы $\mathrm{F}_{7 / 2} \rightarrow \mathrm{F}_{5 / 2}$, наблюдаемое при длине волны порядка $980 \mathrm{~nm}$ [30]. Работ по изучению люминесценции иттербия в оксидных матрицах не много [31-34], и мы не нашли ни одной работы по фотолюминесценции для диоксида циркония с ГЦК-структурой типа флюорита. Целью настоящего исследования является изучение расщепления полосы люминесценции катиона иттербия в оксидной матрице со структурой флюорита $\mathrm{Zr}(\mathrm{Yb}) \mathrm{O}_{2}$. Люминесценция изучена на приборах для исследования комбинационного рассеяния света, как проявление эффектов в области больших волновых чисел. 


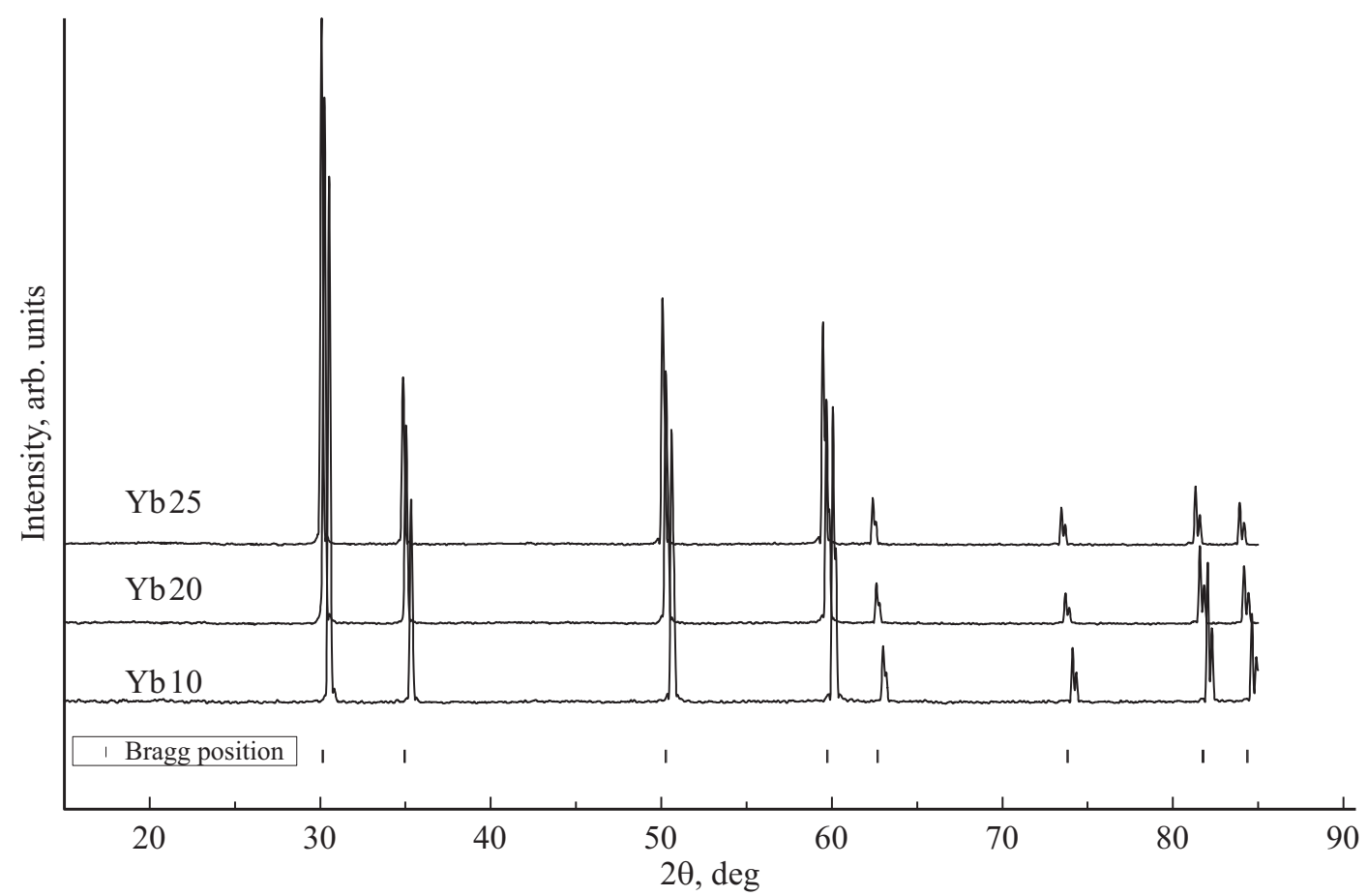

Рис. 1. Диффрактограммы исследованных образцов. Вертикальными штрихами обозначены позиции линий согласно описания в группе симметрии $F m \overline{3} m$.

\section{2. Экспериментальная часть}

\section{1. Изготовление образцов}

Образцы изготовлены методом обратного соосаждения гидроксидов в водном растворе аммиака. Исходными материалами служили: оксихлорид циркония $\mathrm{ZrOCl}_{2} \cdot 8 \mathrm{H}_{2} \mathrm{O}$ (99\%), оксид иттербия (99.995\%), азотная кислота $(99 \%)$ и водный раствор аммиака. Раствор аммиака готовили путем растворения газообразного аммиака в дистиллированной воде; оксид иттербия растворяли в азотной кислоте. Осадок гидроксидов промывали дистиллированной водой и этанолом, высушивали при $120^{\circ} \mathrm{C}$, растирали, прокаливали при $750^{\circ} \mathrm{C}$, вновь растирали, прессовали образцы диаметром $15 \mathrm{~mm}$ при давлении $200 \mathrm{MPa}$ и спекали в вакуумной печи при $1900^{\circ} \mathrm{C}(1 \mathrm{~h})$. После вакуумной печи образцы были отожжены на воздухе при $1650^{\circ} \mathrm{C}(5 \mathrm{~h})$.

Для выделения эффектов, обусловленных именно иттербием, были использованы образцы коммерческой керамики диоксида циркония, допированные десятью процентами оксида иттрия.

\section{2. Рентгеновские исследования}

Аттестацию и контроль фазового состава образцов проводили методом порошкового рентгенофазового анализа (РФА) на дифрактометре Rigaku D/MAX-2200VL/PC (RIGAKU) в $\mathrm{Cu}-K_{\alpha}$ излучении $(\lambda=1.5418 \AA)$ с шагом $\Delta 2 \theta \approx 0.02^{\circ}$ при угловой скорости сканирования $1.2 \% \mathrm{~min}$ на комнатной темпера- туре в атмосфере воздуха. Анализ фазового состава и расчет кристаллографических параметров осуществляли с использованием программного пакета MDI Jade 6.5 (Materials Data Incorporated. 2551 Second Street Livermore, California 94550, 2011) и базы данных PDF-2 ICDD (Powder Diffraction File PDF2 ICDD Release 2004).

\section{3. Исследования методом комбинационного рассеяния света}

Исследования методом комбинационного (рамановского) рассеяния света проведены на двух разных приборах:

- в зеленом излучении $(\lambda=532 \mathrm{~nm})$ на оборудовании Renishaw U 1000 microscope-spectrometer. Мощность $\mathrm{Nd}$ : YAG лазера составляла $50 \mathrm{~mW}$;

- в красном излучении $(\lambda=785 \mathrm{~nm})$ на InVia Reflex с микроскопом Leica DM2700. Мощность Renishaw diode laser с интегрированным плазменным фильтром составляла $300 \mathrm{~mW}$.

Время накопления спектра - от 10 до 30 s при числе проходов от 5 до 16.

\section{3. Результаты и обсуждение}

Результаты дифракционных экспериментов представлены на рис. 1. Структура образцов может быть описана как кубическая, с группой симметрии $F m \overline{3} m$, $\left(\mathrm{Zr}_{0.8} \mathrm{Yb}_{0.2} \mathrm{O}_{1.9}\right.$ PDF № 78-1309). Параметры решетки, 
Таблица 1. Параметры кубической решетки образов $(1-x) \mathrm{ZrO}_{2}+x \mathrm{Yb}_{2} \mathrm{O}_{3}$ и образца сравнения $0.9 \mathrm{ZrO}_{2}+0.1 \mathrm{Y}_{2} \mathrm{O}_{3}$

\begin{tabular}{c|c|c|c|c}
\hline Образец & $\mathrm{Yb} 10$ & $\mathrm{Yb} 20$ & $\mathrm{Yb} 25$ & $\mathrm{YSZ} 10$ \\
\hline Состав & $0.1 \mathrm{Yb}_{2} \mathrm{O}_{3}+0.9 \mathrm{ZrO}_{2}$ & $0.2 \mathrm{Yb}_{2} \mathrm{O}_{3}+0.8 \mathrm{ZrO}_{2}$ & $0.25 \mathrm{Yb}_{2} \mathrm{O}_{3}+0.75 \mathrm{ZrO}_{2}$ & $0.1 \mathrm{Y}_{2} \mathrm{O}_{3}+0.9 \mathrm{ZrO}_{2}$ \\
\hline$a, \AA$ & $5.110(3)$ & $5.136(2)$ & $5.1514(7)$ & $5.152(1)$
\end{tabular}

Таблица 2. Полосы, частота $v\left(\mathrm{~cm}^{-1}\right)$ и полуширина $D\left(\mathrm{~cm}^{-1}\right)$, наблюдаемые на образцах в области больших волновых чисел при возбуждении разными источниками света

\begin{tabular}{|c|c|c|c|c|c|c|c|c|c|c|c|c|c|c|c|}
\hline & \multicolumn{4}{|c|}{$\mathrm{Yb} 10$} & \multicolumn{4}{|c|}{$\mathrm{Yb} 20$} & \multicolumn{4}{|c|}{$\mathrm{Yb} 25$} & \multirow{3}{*}{$\begin{array}{l}\text { YSZ } 10 \\
532 \mathrm{~nm}\end{array}$} & \multicolumn{2}{|c|}{ Люминесценция } \\
\hline & \multicolumn{2}{|c|}{ Red, $785 \mathrm{~nm}$} & \multicolumn{2}{|c|}{ Green, $532 \mathrm{~nm}$} & \multicolumn{2}{|c|}{ Red, $785 \mathrm{~nm}$} & \multicolumn{2}{|c|}{ Green, $532 \mathrm{~nm}$} & \multicolumn{2}{|c|}{ Red, $785 \mathrm{~nm}$} & \multicolumn{2}{|c|}{ Green, $532 \mathrm{~nm}$} & & \multirow[t]{2}{*}{$\lambda, \mathrm{nm}$} & \multirow[t]{2}{*}{$E, \mathrm{eV}$} \\
\hline & $v$ & $D$ & $v$ & $D$ & $v$ & $D$ & $v$ & $D$ & $v$ & $D$ & $v$ & $D$ & & & \\
\hline & & & & & & & 1683.0 & 121.4 & & & & & & & \\
\hline & & & & & & & 1704.7 & 42.4 & & & & & & & \\
\hline LG1 & & & 1711.7 & 18.0 & & & 1712.6 & 18.4 & & & 1710.6 & 22.8 & 1711.9 & 585.3 & 2.118 \\
\hline LG2 & & & 1762.3 & 51.1 & & & 1759.5 & 75.0 & & & 1752.3 & 93.1 & 1753.0 & 586.9 & 2.112 \\
\hline \multirow{2}{*}{ A1 } & \multirow{2}{*}{1768.9} & \multirow{2}{*}{236.4} & 1770.3 & 12.8 & & & & & & & & & & \multirow{2}{*}{-} & \multirow{2}{*}{-} \\
\hline & & & 1773.0 & 105.8 & & & & & & & & & & & \\
\hline LG3 & & & 1822.4 & 53.7 & & & 1824.8 & 54.3 & & & 1830.1 & 47.0 & - & 589.2 & 2.104 \\
\hline LG4 & & & 1871.7 & 60.0 & & & 1871.4 & 65.9 & & & 1870.3 & 63.6 & 1863.8 & 590.8 & 2.098 \\
\hline LG5 & & & 1957.6 & 111.6 & & & 1954.3 & 121.3 & & & 1950.0 & 120.9 & - & 593.7 & 2.088 \\
\hline LG6 & & & 2073.4 & 528.4 & & & 2067.3 & 124.8 & & & 2036.1 & 184.6 & - & 597.5 & 2.075 \\
\hline LR1 & 2134.9 & 362.6 & & & 2137.1 & 296.1 & & & 2149.8 & 253.4 & & & & 942.9 & 1.315 \\
\hline LG7 & & & 2225.1 & 58.5 & & & 2238.9 & 54.4 & & & 2227.2 & 60.8 & - & 603.6 & 2.054 \\
\hline \multirow{2}{*}{$\mathrm{X} 1$} & \multirow{2}{*}{2263.7} & \multirow{2}{*}{90.9} & \multirow{2}{*}{2295.7} & \multirow{2}{*}{97.4} & \multirow{2}{*}{2288.1} & \multirow{2}{*}{92.0} & 2309.7 & 102.0 & \multirow{2}{*}{2292.0} & \multirow{2}{*}{80.8} & \multirow{2}{*}{2267.7} & 023 & 2281.3 & & \\
\hline & & & & & & & 2327.7 & 5.4 & & & & 92.5 & & - & - \\
\hline $\mathrm{X} 2$ & 2367.9 & 49.7 & 2387.0 & 136.0 & 2387.7 & 50.8 & 2423.1 & 93.4 & 2390.8 & 43.1 & 2368.3 & 31.2 & & - & - \\
\hline (?) & & & & & & & 2424.4 & 537.3 & & & 2406.3 & 158.9 & & & \\
\hline & & & & & 2462.0 & 202.8 & & & & & & & & & \\
\hline LR2 & 2428.6 & 24.0 & & & 2436.9 & 43.2 & & & & & & & & & \\
\hline MAX & 2447.8 & 107.1 & & & 2444.7 & 75.9 & & & 2441.9 & 57.8 & & & & 971.7 & 1.276 \\
\hline $\mathrm{A} 2$ & 2562.7 & 124.3 & 2557.9 & 342.7 & & & & & 2454.7 & 193.3 & & & & - & - \\
\hline LR3 & 2668.1 & 209.6 & & & 2693.0 & 201.1 & & & 2690.3 & 228.4 & & & & 993.1 & 1.248 \\
\hline & & & & & & & 2719.7 & 320.8 & & & & & & & \\
\hline LG8 & & & 2922.7 & 124.1 & & & 2917.9 & 192.2 & & & 2947.5 & 161.1 & & 630.2 & 1.967 \\
\hline LG9 & & & 3025.3 & 78.6 & & & 3007.4 & 146.3 & & & 3000.8 & 85.3 & 2995.7 & 633.4 & 1.957 \\
\hline
\end{tabular}

совместно с их наименованием и химическим составом, приведены в табл. 1.

Результаты исследования образцов методом комбинационного рассеяния света представлены на рис. 2 и 3. На рис. 2 результаты с применением зеленого $(\lambda=532 \mathrm{~nm})$ лазера демонстрируют кроме хорошо известных в литературе, например [25], линий в области до $800 \mathrm{~cm}^{-1}$, набор полос в области волновых чисел 
больше одной тысячи обратных сантиметров. Рефлексы в этой области частот обычно идентифицируют как проявление люминесценции. На рис. 3 представле-

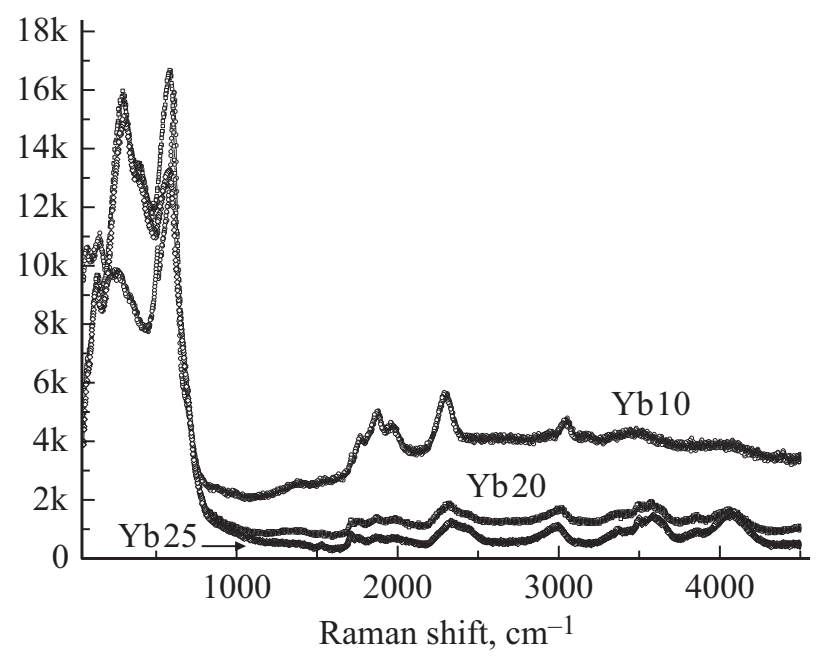

Рис. 2. Спектры комбинационного рассеяния света. $\lambda=532 \mathrm{~nm}$
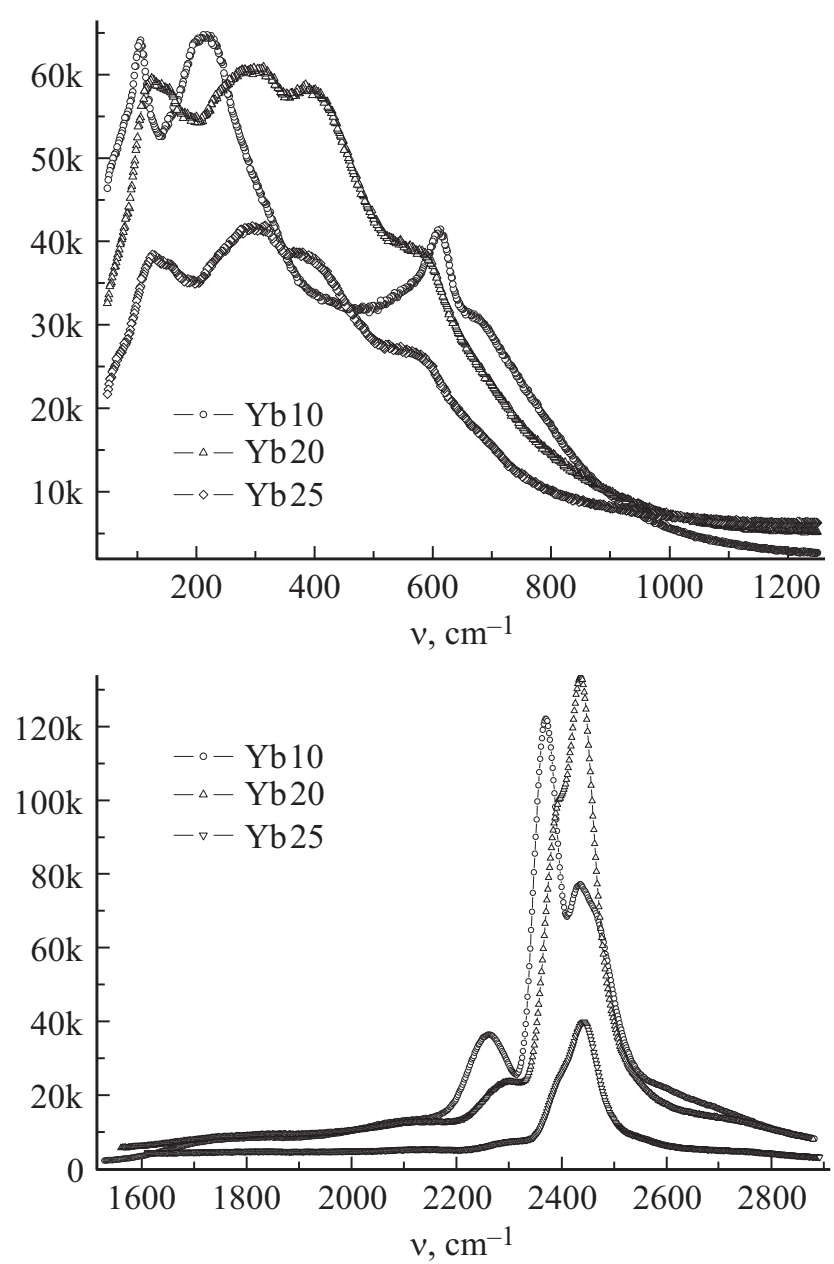

Рис. 3. Спектры комбинационного рассеяния света при использовании красного $(\lambda=785 \mathrm{~nm})$ лазера образцов. Вверху область малых волновых чисел, внизу - больших.

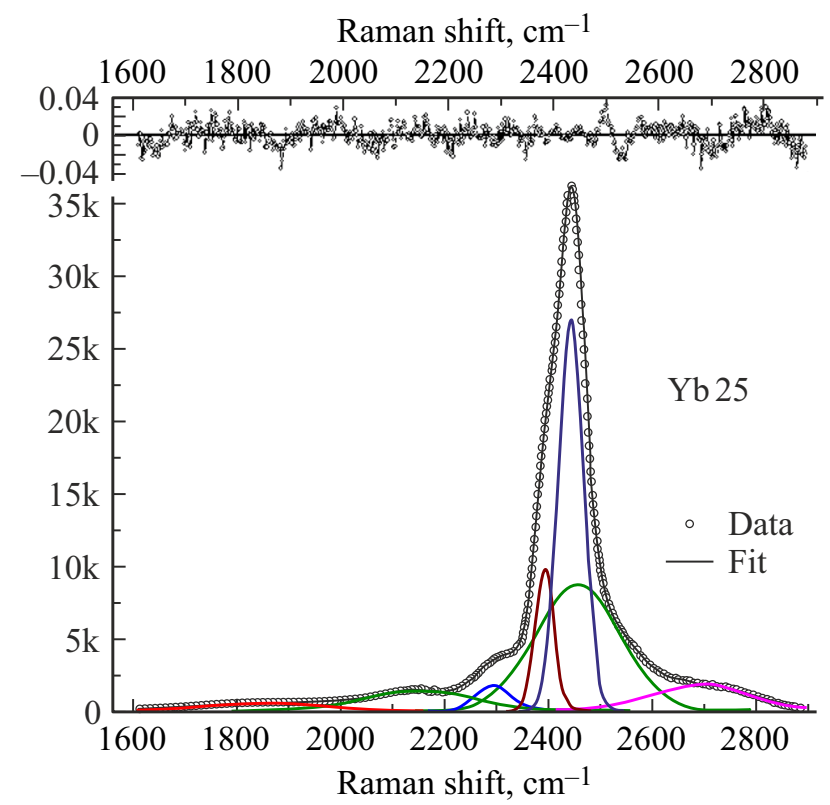

Рис. 4. Пример описания спектра образца Yb25 совокупность гауссовских полос. В верхней части рисунка представлена относительная погрешность.

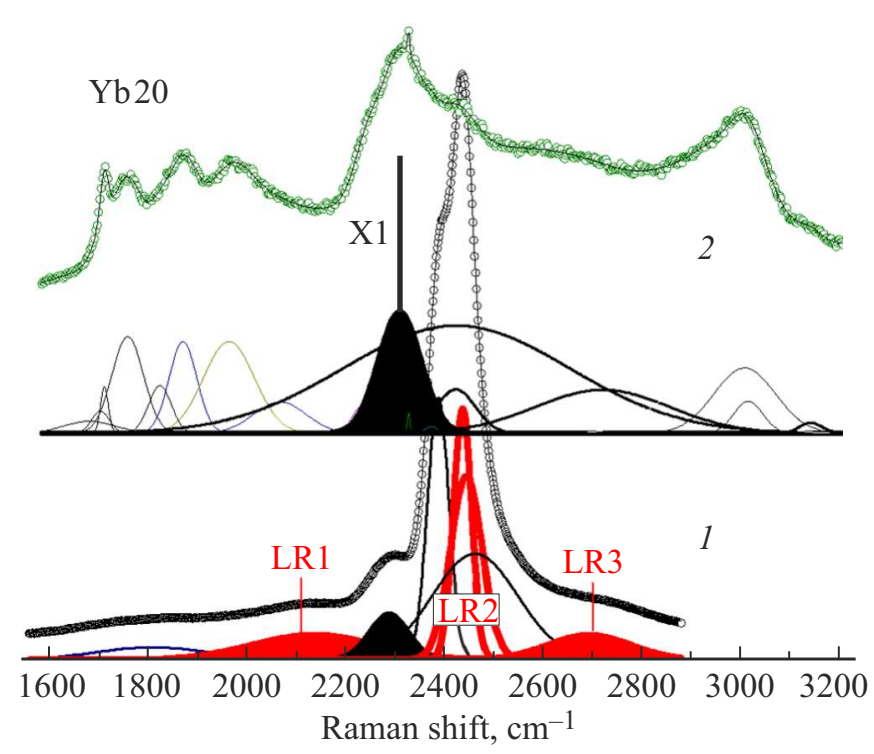

Рис. 5. Сравнение спектров в красном (1) и зеленом (2) излучении для образца $\mathrm{Yb} 20$. Полоса $\mathrm{X} 1$ присутствует в обоих спектрах. Полосы LR1-LR3 присутствуют только в спектрах при использовании красного лазера.

ны результаты исследования с применением красного $(\lambda=785 \mathrm{~nm})$ лазера. В длинноволновой части спектра при волновых числах 2300-2600 наблюдается мультиплет очень большой интенсивности, обусловленный люминесценцией, вызванной переходом $\mathrm{F}^{7 / 2} \rightarrow \mathrm{F}^{5 / 2}$ катиона иттербия [29-34].

C применением программного комплекса „Peak separation $2^{\text {“ }}$ наблюдаемые спектры были описаны со- 

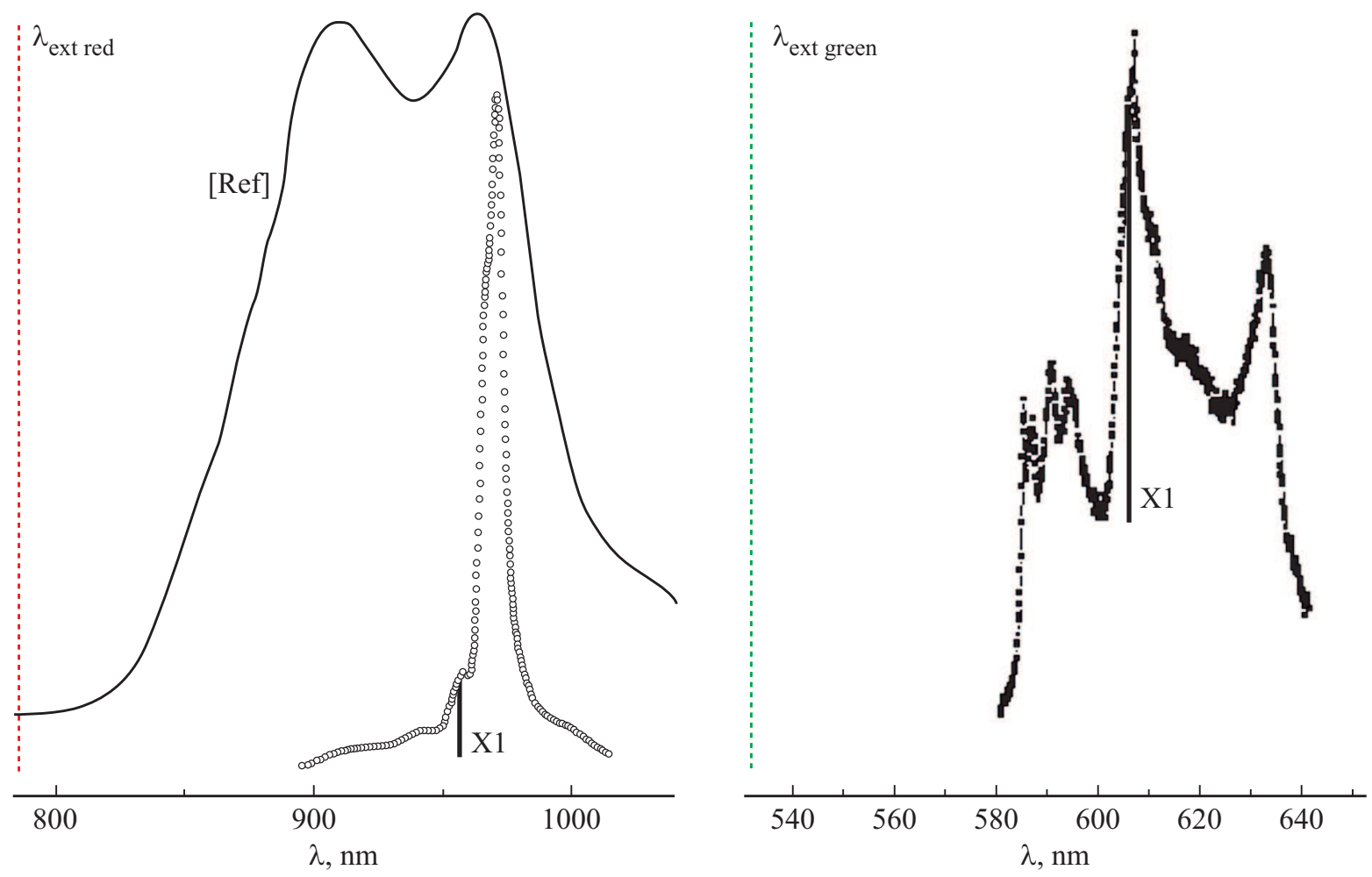

Рис. 6. Спектры люминесценции, полученные в красном (слева) и зеленом (справа) излучении. Вертикальная пунктирные линии показывают длину волны возбуждающего излучения. Толстой линией Х1 показана стоксовская полоса. Для сравнения представлен спектр (Ref) для рентгеностимулированной люминесценции состава, аналогичного Yb20 [34].

вокупностью линий гауссовой формы. Пример такого описания представлен на рис. 4. Совокупность результатов, полученных как с применением красного $(\lambda=785 \mathrm{~nm})$, так и зеленого $(\lambda=532 \mathrm{~nm})$ лазеров, представлена в табл. 2. Ряд полос, обозначенных в табл. 2 как LR1-LR3, наблюдаются только в спектрах красного лазера (рис. 5), а ряд полос, обозначенных как LG1-LG9, только в спектрах зеленого лазера. Вместе с тем отметим, что наблюдаются рефлексы, присутствующие одновременно как в спектрах красного, так и зеленого лазеров (X1 на рис. 5). Это указывает на стоксовский характер таких линий. В этой области волновых чисел наблюдают только стоксовские линии высокого порядка [35]. Насколько нам известно, для допированного диоксида циркония такой эффект сообщается впервые.

Стоксовская линия X1 (рис. 6) имеет высокую интенсивность. Она, конечно, слабее чем полоса, вызванная переходом $\mathrm{F}^{7 / 2} \rightarrow \mathrm{F}^{5 / 2}$ катиона иттербия при возбуждении красным лазером, но она сильнее чем все полосы люминесценции, наблюдаемые в зеленом лазере (рис. 6).

По-видимому, полоса X1 не является единственной стоксовской линей для этих материалов. На рис. 7 представлено сравнение спектров, полученных как с применением красного $(\lambda=785 \mathrm{~nm})$, так и зеленого $(\lambda=532 \mathrm{~nm})$ лазеров. Кроме интенсивной полосы X1, наблюдаются так же и две полосы A1 и A2, которые имеют существенно меньшую интенсивность, но они, повидимому, тоже имеют стоксовский характер, так как присутствуют в спектра, полученных как с применением

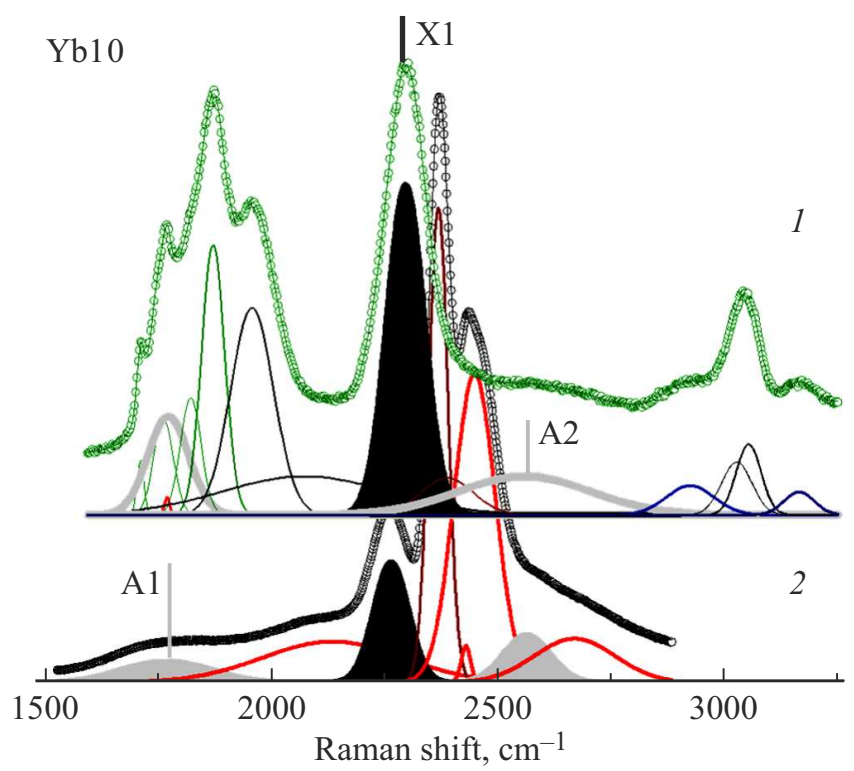

Рис. 7. Сравнение спектров в красном (1) и зеленом (2) излучении для образца $\mathrm{Yb} 10$. Полоса X1 присутствует в обоих спектрах для всех составов, а полосы А1 и А2 только для $\mathrm{Yb} 10$. 
красного, так и зеленого лазеров. В отличие от полосы X1, которая присутствует в спектрах всех составов, линии А1 и А2 присутствуют только для состава Yb10.

Полоса, вызванная переходом $\mathrm{F}^{7 / 2} \rightarrow \mathrm{F}^{5 / 2}$ катиона иттербия, наблюдается при использовании красного лазера для всех образцов, содержащих иттербий (табл. 2), и отсутствует для образца, допированного иттрием. Она является источником самой сильной люминесценции для данных образцов и описана в литературе. Новым результатом является расщепление этой полосы на хорошо разделенный триплет LG1-LG3 (рис. 5), из которых полоса LG2 сама, по-видимому, является мультиплетом. Подобное расщепление ранее было изучено для катиона иттербия в матрице $\mathrm{CaF}_{2}$, которая изоструктурна исследуем нами материалам [30]. Анализ такого расщепления дает исследуемым перспективы изучения окружения катиона иттербия.

Люминесценция под действием зеленого лазера имеет малую интенсивность. Гипотетически источником такой люминесценции может так же служить катион иттербия, для которого ранее сообщались, пусть и слабые по интенсивности, эффекты [29,36-39]. Альтернативной причиной может являться люминесценция, обусловленная радиационными переходами между зоной проводимости и ловушечными состояниями допированного диоксида циркония, такими как кислородная вакансия $V_{0}$, связанные комплексы кислородной вакансии и допирущего катиона [40-42]. Подобные эффекты не связаны с катионом иттербия и будут объектом дальнейшего изучения.

\section{4. Заключение}

Изучены спектры комбинационного рассеяния света для образцов диоксида циркония, допированных 10, 20 и $25 \%$ оксида иттербия в области больших волновых чисел. Были использованы два разных монохроматических источника с различной длинной волны $(532$ и $785 \mathrm{~nm})$, что позволяет выделять стоксовские линии. Полоса, вызванная переходом $\mathrm{F}^{7 / 2} \rightarrow \mathrm{F}^{5 / 2}$ катиона иттербия, наблюдается при использовании красного лазера. Впервые для оксидной матрицы со структурой флюорита описано ее расщепление (рис. 5).

Показано наличие стоксовских линий, проявление которых не зависит от длины волны использованного источника. Для оксидных материалов со структурой флюорита в этой области волновых чисел это сделано впервые. Линии интерпретированы как стоксовские рефлексы высокого порядка.

Подтверждена люминесценция под действием зеленого лазера, существование которой описано ранее.

\section{Благодарности}

Исследование выполнено с использованием оборудования центра коллективного пользования Института высокотемпературной электрохимии УрО РАН при участии
А. Ахмадеева. Авторы признательны В.П. Горелову за предоставление образцов.

\section{Финансирование работы}

Исследование выполнено в рамках программы бюджетного финансирования (номер регистрации темы АААА-А19-119020190044-1) в ИВТЭ УрО РАН.

\section{Конфликт интересов}

Авторы заявляют об отсутствии конфликта интересов.

\section{Список литературы}

[1] В.Н. Чеботин, М.В. Перфильев. Электрохимия твердых электролитов. Химия, М. (1978). 312 c. [Republished by Washington: Technical Information Center, U.S. Department of Energ (1984).].

[2] М.В. Перфильев, А.К. Демин, Б.Л. Кузин, А.С. Липилин. Высокотемпературный электролиз газов. Наука, М. (1988). $232 \mathrm{c}$.

[3] В.Н. Чеботин. Химическая диффузия в твердых телах. Наука, М. (1989). 208 с.

[4] M. Balkanski, T. Takahashi, H. Tuller. Solid State Ionics. Elsevier, Amsterdam (1992). 345 p.

[5] А.К. Иванов-Шиц, И.В. Мурин. Ионика твердого тела. СПбГУ, СПб (2000). Т. 1.616 с.

[6] S.C. Singha, K. Kendall. High temperature solid oxide fuel cells: fundamentals, design and applications. Elsevier (2003). $429 \mathrm{p}$.

[7] J. Maier. Physical chemistry of ionic materials: ions and electrons in solids. John Wiley \& Sons (2004). 539 p.

[8] А.К. Иванов-Шиц, И.В. Мурин. Ионика твердого тела. СПбГУ, СПб (2010). Т. 2. 1000 c.

[9] F. Ramadhani, M.A. Hussain, H. Mokhlis, S. Hajimolana. Renew. Sust. Energ. Rev. 76, 460 (2017).

[10] T. Liu, X. Zhang, X. Wang, J. Yu, L. Li. Ionics 22, 2249 (2016).

[11] С.Н. Шкерин. Изв. РАН. Сер. физ. 66, 890 (2002).

[12] S. Shkerin. Fuel Cell Technologies: State and Perspectives, NATO Science Ser. Mathematics, Physics and Chemistry. Springer 202, 301 (2005).

[13] V. Ivanov, S. Shkerin, A. Rempel, V. Khrustov, A. Lipilin, A. Nikonov. J. Nanosci. Nanotechnol. 10, 11, 7411 (2010).

[14] В.В. Иванов, С.Н. Шкерин, Ал.А. Ремпель, В.Р. Хрустов, А.С. Липилин, А.В. Никонов. Докл. РАН 433, 2, 206 (2010).

[15] А.Н. Власов. Электрохимия 25, 5, 699 (1989).

[16] А.Н. Власов. Электрохимия 25, 10, 1313 (1989).

[17] А.Н. Власов. И.Г. Шулик. Электрохимия 26, 7, 909 (1990).

[18] А.Н. Власов. Электрохимия 19, 2, 1624 (1983).

[19] А.Н. Власов, М.В. Иноземцев. Электрохимия 21, 6, 764 (1985).

[20] A. Vlasov, M.V. Perfiliev. Solid State Ionics 25, 245 (1987).

[21] А.Н. Власов. Электрохимия 27, 11, 1479 (1991).

[22] М.А. Борик, А.В. Кулебякин, И.Е. Курицына, Е.Е. Ломонова, В.А. Мызина, П.А. Попов, Ф.О. Милович, Н.Ю. Табачкова. ФТТ 61, 12, 2390 (2019). 
[23] Д.А. Агарков, М.А. Борик, Г.М. Кораблева, А.В. Кулебякин, И.Е. Курицына, Е.Е. Ломонова, Ф.О. Милович, В.А. Мызина, П.А. Попов, П.А. Рябочкина. ФТТ 62, 12, 2093 (2020).

[24] V.G. Keramidas, W.B. White. J. Chem. Phys. 59, 3, 1561 (1973).

[25] Е.Е. Ломонова, Д.А. Агарков, М.А. Борик, Г.М. Елисеева, А.В. Кулебякина, И.Е. Курицына, Ф.О. Милович, В.А. Мызина, В.В. Осико, А.С. Числов, Н.Ю. Табачкова. Электрохимия 56, 2, 127 (2020).

[26] D.A. Long. The Raman effect: A unified treatment of the theory of raman scattering by molecules. John Wiley \& Sons Ltd (2002). 610 p.

[27] J. Cui, G. Hope. J. Spectrosc. (Hindawi) 2015, Article ID 940172 (2015). http://dx.doi.org/10.1155/2015/940172

[28] С.Н. Шкерин, Е.С. Юльянова, Э.Г. Вовкотруб. Неорган. материалы 57, 11, 1213 (2021).

[29] Ю.К. Воронько, Б.И. Денкер, В.В. Осико. ФТТ 13, 8, 2193 (1971).

[30] T. Kallel, M.A. Hassairi, M. Dammak, A. Lyberis, P. Gredin, M. Mortier. J. Alloys Compd. 584, 261 (2014).

[31] W. Tang, Y. Wang, C.-L. Jia. ФTT 63, 1, 110 (2021).

[32] Y. Yu, Y. Huang, L. Zhang, Z. Lin, G. Wang. PLoS ONE 8, 1, e54450 (2013). doi: 10.1371/journal.pone.0054450

[33] L. Zhenzhang, Z. Shaoan, X. Qinfang, D. He, L. Yang, L. Xiaohui, W. Chuanlong, J. Jin, H. Yihua. J. Alloys Compd. 766, 663 (2018).

[34] R. Khabibrakhmanov, A. Shurukhina, A. Rudakova, D. Barinov, V. Ryabchuk, A. Emeline, G. Kataeva, N. Serpone. Chem. Phys. Lett. 742, 137136 (2020).

[35] S. Prawer, R. Nemanich. Phil. Trans. R. Soc. A. 362, 2537 (2004).

[36] G. Broden, S.B.Y. Hagstrom T.L. Loucks. Phys. Rev. Lett. 21, 1524 (1968).

[37] J.G. Endriz, W.E. Spicer. Phys. Rev. B 2, 1466 (1970).

[38] P.O. Heden, H. Lofgren, S.G.Y. Hagstrom. Phys. Status Solidi B 49, 721 (1972).

[39] Y. Baer, G. Busch. J. Electron Spectrosc. Rel. Phenom. 5, 627 (1974).

[40] N.G. Petrik, D.P. Taylor, T.M. Orlando. J. Appl. Phys. 85, 6770 (1999).

[41] Z. Wanga, Z.Q. Chena, J. Zhua, S.J. Wanga, X. Guo. Rad. Phys. Chem. 58, 697 (2000).

[42] J. Costantini, F. Beuneu, M. Fasoli, A. Galli, A. Vedda, M. Martini. J. Phys.: Condens. Matter 23, 11590 (2011).

Редактор Ю.Э. Китаев 